\title{
Impact of COVID-19 Pandemic on Life-Space Mobility of Older Adults Living in Brazil: REMOBILIZE Study
}

\begin{abstract}
Monica R. Perracini ${ }^{1,2 *}$, Juleimar Soares Coelho de Amorim ${ }^{3}$, Camila Astolphi Lima ${ }^{1}$, Alexandre da Silva ${ }^{4}$, Francis Trombini-Souza ${ }^{5}$, Daniele Sirineu Pereira ${ }^{6}$, Paulo Henrique Silva Pelicioni ${ }^{7}$, Etiene Duim ${ }^{8}$, Patricia Parreira Batista ${ }^{6}$, Renato Barbosa dos Santos ${ }^{1}$, Maria do Carmo Correia de Lima $^{2}$ and the REMOBILIZE Research Network (CANSORT-SCI)

'Master's and Doctoral Program in Physical Therapy, Universidade Cidade de São Paulo, São Paulo, Brazil, ${ }^{2}$ Master's and Doctoral Programs in Gerontology, Faculty of Medical Sciences, Universidade Estadual de Campinas, Campinas, Brazil, ${ }^{3}$ Physiotherapy Undergraduate Program, Instituto Federal do Rio de Janeiro, Rio de Janeiro, Brazil, ${ }^{4}$ Department of Collective Health, Faculdade de Medicina de Jundiaí, Jundiaí, Brazil, ${ }^{5}$ Master's and Doctoral Program in Rehabilitation and Functional Performance, Universidade de Pernambuco, Petrolina, Brazil, ${ }^{6}$ Department of Physical Therapy, Universidade Federal de Minas Gerais, Belo Horizonte, Brazil, ${ }^{7}$ Division of Health Sciences, School of Physiotherapy, University of Otago, Dunedin, New Zealand, ${ }^{8}$ Department of Diagnostic and Ambulatory Medicine, Hospital Israelita Albert Einstein, São Paulo, Brazil
\end{abstract}

OPEN ACCESS

Edited by:

Marcia G. Ory,

Texas A\&M University, United States

Reviewed by:

Aya Yoshikawa,

Texas A\&M University, United States Andiara Schwingel,

University of llinois at

Urbana-Champaign, United States

*Correspondence:

Monica R. Perracini monica.perracini@unicid.edu.br

Specialty section:

This article was submitted to Aging and Public Health,

a section of the journal Frontiers in Public Health

Received: 18 December 2020 Accepted: 11 March 2021 Published: 09 April 2021

Citation:

Perracini MR, de Amorim JSC, Lima CA, da Silva A,

Trombini-Souza F, Pereira DS,

Pelicioni PHS, Duim E, Batista PP, dos Santos RB, de Lima MdCC and the REMOBILIZE Research Network (CANSORT-SCI) (2021) Impact of COVID-19 Pandemic on Life-Space Mobility of Older Adults Living in Brazil: REMOBILIZE Study.

Front. Public Health 9:643640.

doi: $10.3389 /$ fpubh.2021.643640
Background: The COVID-19 pandemic hit Brazil in a scenario of substantial socioeconomic and health inequalities. It is unknown the immediate impact of social restriction recommendations (i.e., lockdown, stay-at-home) on the life-space mobility of older people.

Objective: To investigate the immediate impact of COVID-19 pandemic on life-space mobility of community-dwelling Brazilian older adults and examine the social determinants of health associated with change in life-space mobility.

Design: Baseline data from a prospective cohort study (REMOBILIZE Study).

Setting: Community.

Subject: A convenience snowball sample of participants aged 60 and older $(n=1,482)$ living in 22 states in Brazil.

Methods: We conducted an online and phone survey using an adapted version of the Life-Space Assessment (LSA). Linear regression models were used to investigate social determinants of health on the change in LSA score.

Results: Regardless of their gender and social determinants of health, participants showed a significant reduction in life-space mobility since COVID-19 pandemic outbreak. Life-space mobility reduction was higher among black individuals, those living alone and aged between 70 and 79 . Other variables associated with change in life-space mobility, to a lesser extent, were sex, education and income.

Conclusion: Social restriction measures due to pandemic caused substantial reduction in older adults' life-space mobility in Brazil. Social inequalities strongly affected vulnerable groups. Concerted actions should be put in place to overcome the deterioration in life-pace mobility amongst these groups. Failure in minimizing health inequalities amplified by the pandemic may jeopardize the desired achievements of the Decade of Healthy Aging.

Keywords: participation, COVID-19, social distancing, health status disparities, well-being 


\section{INTRODUCTION}

Experts agree that older people are the group most affected by the COVID-19 pandemic $(1,2)$. Worldwide, more than $66 \%$ of adults aged 70 years and over have underlying conditions and are at higher risk for severe disease, which may result in hospitalization and death (3). Social restriction recommendations (i.e., lockdowns, social distancing, stay-athome orders) have been set up as population-level measures to suppress community transmission of COVID-19 (4). Although these measures were adopted worldwide, how different groups of older people adapted their life-space mobility to these new circumstances (5) is still uncertain. Varying housing conditions, social inequalities, and governments' response policies may have affected how older people moved around since the COVID-19 pandemic (6-8).

Life-space mobility is not a new concept (9); it corresponds to how people engage in, maintain social relationships and roles, and participate in meaningful activities within their communities (10). It is recognized as a practical measure to capture older people's functional ability for moving around in their environments in a specific period of time (11). Restriction of life-space mobility occurs due to a combination of losses in individuals intrinsic capacity, limited personal resources, and difficulty dealing with environmental challenges, resulting in potentially health adverse outcomes (9).

Restrictions in life-space mobility $(12,13)$ and in active aging scores (12) were observed in community-dwelling older people during the COVID-19 pandemic. Active aging was evaluated using a novel scale that encompasses older people's striving for well-being through activities pertaining to their goals, abilities, and opportunities (14). Declines in life-space mobility and active aging unsurprisingly coincided, since social restriction policies may have reduced opportunities for several out-of-home activities (12).

Foreseen consequences of constriction in life-space mobility observed in previous studies are decreased levels of physical activity $(15,16)$, higher prevalence of depressive symptoms (17), cognitive decline $(18,19)$, poor physical capacity $(11)$, obesity (6), and increased risk for developing frailty (9). Particularly, inactivity related to deconditioning $(20,21)$ increases the risk of health deterioration associated with chronic non-communicable diseases $(21,22)$ and may accelerate the loss of muscle mass and muscle strength, along with the accumulation of body fat. Ultimately, inactivity results in poorer overall health (23).

Social inequalities may contribute to the negative impact of social restriction recommendations on life-space mobility since COVID-19 pandemic, particularly for older people living in low-resource settings (24). Previous studies have shown that lower life-space mobility scores were associated with female sex, low educational level, insufficient income $(6,7,11)$, and poor physical and social environments (7). Underlying inequalities of gender, race/ethnicity, income, and residential segregation may expose vulnerable groups of older people to negative consequences of the COVID-19 pandemic (25).
Our hypothesis is that levels of life-space mobility throughout the pandemic will exhibit different trajectories according to social determinants. Investigating how social factors influence life-space mobility in this unique period can help to develop interventions needed to deal with the deleterious effects of the COVID-19 pandemic on health systems, individuals, and their families $(20,26,27)$. Therefore, this study (i) investigated the immediate impacts of COVID-19 pandemic on the life-space mobility of community-dwelling Brazilian older adults; and (ii) examined the social determinants of health associated with change in life-space mobility.

\section{METHODS}

\section{Study Design, Setting, and Participants}

We used baseline data from the REMOBILIZE study, which involved a cohort survey to investigate life-space mobility throughout the course of the COVID-19 pandemic and used a task-force research network for a 12-month follow-up period. We surveyed a convenience snowball sample of older adults aged 60 and older $(n=1,482)$ living in $22(82 \%)$ states in Brazil, using the online platform SurveyMonkey ${ }^{\circledR}$. We used social media (Facebook ${ }^{\circledR}$ and Instagram ${ }^{\circledR}$ ) and WhatsApp ${ }^{\circledR}$ to recruit participants. A website was set up to reinforce the legitimacy of the study and to provide a central address for respondents to contact the research team. We contacted community leaders and allied health professionals working in vulnerable regions to include participants with different educational and income levels, ethnicities, and genders. We excluded bedridden participants and older adults living in long-term care facilities. Older adults with cognitive decline or who were unable to answer interview questions due to visual or other difficulties, such as digital illiteracy, were helped by a proxy-either a family, friend, or formal caregiver. We conducted data collection between May 18th, 2020 and July 4th, 2020, and participants took approximately $30 \mathrm{~min}$ to complete the survey.

The Ethical Research Committee of Universidade Cidade de São Paulo approved all research procedures (protocol number 4.032.523). A consent form was included in the online survey questionnaire as well as given in interviews conducted by telephone. Participants consented or declined to participate in the study by selecting an on-screen button.

\section{Measures \\ Life-Space Mobility}

Life-space mobility was assessed using a Brazilian Portuguese version of the Life-Space Assessment (LSA; (28). The LSA comprises five life-space levels: (1) rooms other than the bedroom, (2) areas outside the house (i.e., porch, deck, yard, hallway of an apartment building or garage), (3) neighborhood other than own yard or apartment building, (4) outside the neighborhood, but within town; and (5) places outside one's own town.

At the baseline, participants were asked about the places they reached both before the COVID-19 pandemic and a week before evaluation (since the pandemic period). For each level, 
participants were asked how often within the week they attained that level (less than once a week, one to three times a week, four to six times a week, or daily) and whether they needed any help to move to that level (without assistive device or assistance, with an assistive device, or with personal assistance). In the original instrument, displacement is evaluated in the previous 4 weeks, and the respondent is asked to appraise how many times a week he/she attained that place. As most participants in our study answered the questionnaire online without the assistance of an interviewer, we chose to ask about the last week to avoid misinterpretation. Life-space mobility questionnaires have been applied in different timeframes according to specific populations and circumstances $(9,29)$.

A composite score is calculated by multiplying each life-space level reached by the degree of independence and frequency (30). Score range from 0 to 120 points; higher scores represent greater mobility in space $(11,28)$. The original instrument demonstrated a reproducibility of 0.97 (95\% CI $0.95-0.98)$. A moderate negative correlation between LSA scores and accelerometry was observed $(-0.63,95 \%$ CI $-0.74--0.40)(28)$.

\section{Social Factors and Comorbidities}

Independent variables were gender, age group (60-69, 70-79, and $\geq 80$ years), self-report of skin color/race/ethnicity categorized according to official Brazilian classification (white, black, pardo, amarelo, or indigenous), marital status (single, married, divorced, widowed), and education level (illiterate, 1-4 years, 5-8 years, and $\geq 9$ years of schooling), living alone (yes/no), income level presented as the minimum wage per month guaranteed by law in Brazil $(<1,2-3,4-7,8-10$, and $>10$ minimum wage salaries), employment (active, inactive, or unemployed), receiving pension (yes/no), and reported comorbidities using the Functional Comorbidity Index (FCI) questionnaire (31). The FCI is composed of 18 comorbidities related mainly to physical function. Comorbidities were summed up, and older adults with two or more diseases were considered to have multimorbidity (32).

\section{Reported Social Restriction}

Adherence to social restriction measures was captured using a five-point Likert scale question: "Do you think you are following the recommendations for social restriction measures?" Possible responses were strongly agree, partially agree, indifferent, partially disagree, and totally disagree. We also asked participants, "What best describes you at this moment?" Possible responses were "living a normal life, nothing has changed in my daily routine;" "being careful, but going out for work, visiting family members or other activities;" "going out

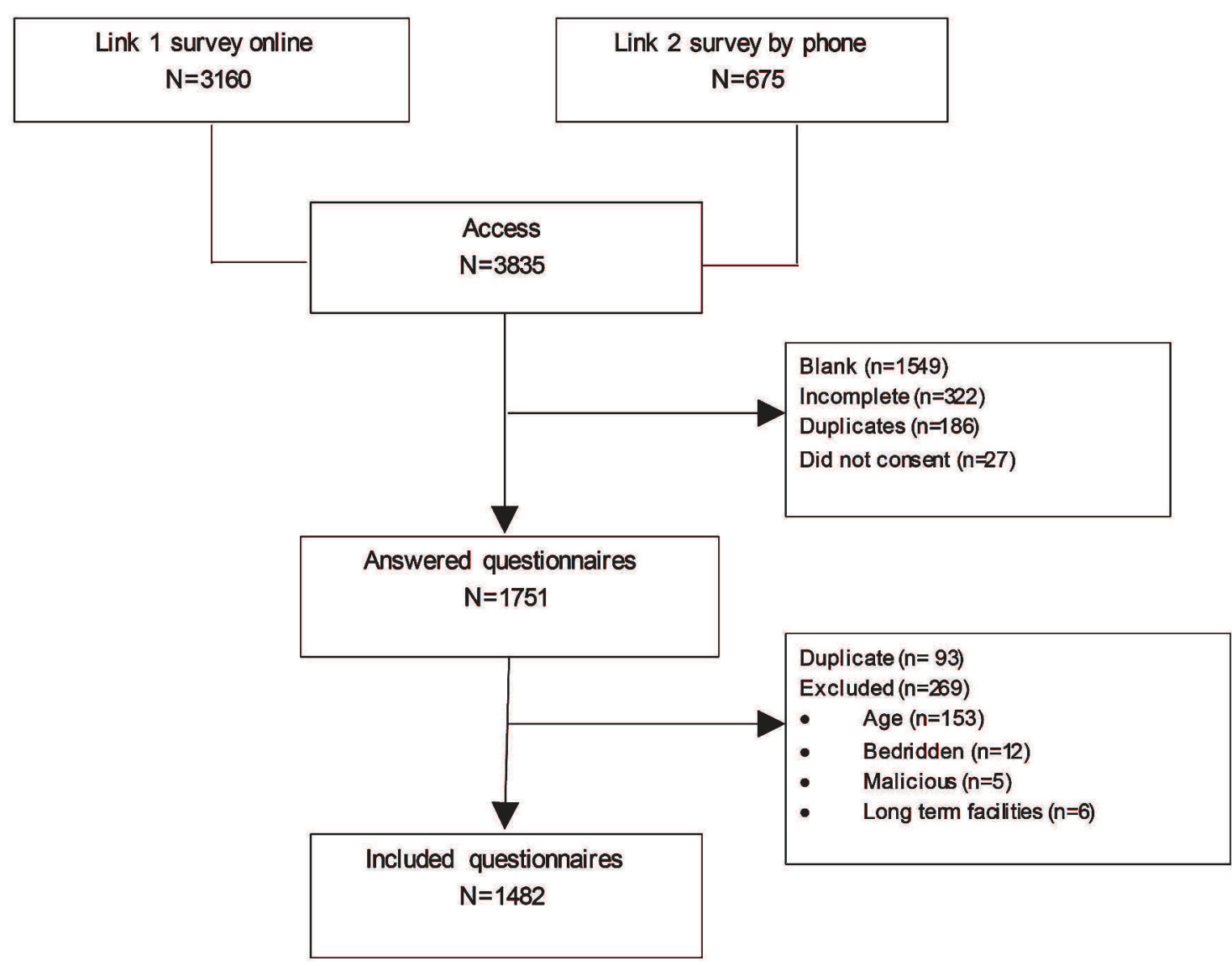

FIGURE 1 | Study flowchart. 
TABLE 1 | Social determinants, multimorbidity and responses to social restriction measures among community-dwelling older people between May and July 2020 (33).

\begin{tabular}{|c|c|}
\hline Characteristic & $N=1,482(\%)$ \\
\hline Female Gender & $1,096(73.9)$ \\
\hline \multicolumn{2}{|l|}{ Age groups (years) } \\
\hline $60-69$ & $831(56.1)$ \\
\hline $70-79$ & $420(28.4)$ \\
\hline 80 and over & $229(15.5)$ \\
\hline \multicolumn{2}{|l|}{ Ethnicity } \\
\hline White & $915(61.7)$ \\
\hline Black & $100(6.8)$ \\
\hline "Pardo" & $439(29.6)$ \\
\hline "Amarelo" & $23(1.6)$ \\
\hline Indigineous & $5(0.3)$ \\
\hline \multicolumn{2}{|l|}{ Marital status } \\
\hline Single & $152(10.3)$ \\
\hline Married & $796(53.7)$ \\
\hline Divorced & $184(12.4)$ \\
\hline Widowed & $350(23.6)$ \\
\hline Living alone & $256(17.3)$ \\
\hline \multicolumn{2}{|l|}{ Educational level (years of schooling) } \\
\hline Illiterate & $117(7.9)$ \\
\hline $1-4$ & $282(19.0)$ \\
\hline $5-8$ & $181(12.2)$ \\
\hline 9 or more & $902(60.9)$ \\
\hline \multicolumn{2}{|l|}{ Income (minimum wage salary) ${ }^{a}$} \\
\hline$<1$ & $512(34.5)$ \\
\hline $2-3$ & $413(27.9)$ \\
\hline $4-7$ & $267(18.1)$ \\
\hline $8-10$ & $114(7.7)$ \\
\hline 10 or more & $176(11.9)$ \\
\hline \multicolumn{2}{|l|}{ Employment } \\
\hline Active & $545(36.8)$ \\
\hline Inactive & $836(56.4)$ \\
\hline Unemployed & $101(6.8)$ \\
\hline Pension (yes) & $1,215(82.0)$ \\
\hline Multimorbidity (two or more) ${ }^{\mathrm{b}}$ & $841(56.8)$ \\
\hline \multicolumn{2}{|l|}{ Following social restriction measures } \\
\hline Strongly and partially disagree & $47(3.2)$ \\
\hline Partially agree & $201(13.6)$ \\
\hline Totally agree & $1,234(83.3)$ \\
\hline \multicolumn{2}{|c|}{ Social restriction behavior since pandemic } \\
\hline $\begin{array}{l}\text { Living without any routine } \\
\text { change }\end{array}$ & $42(2.8)$ \\
\hline $\begin{array}{l}\text { Being careful, but leaving home } \\
\text { to work and visit relatives }\end{array}$ & $169(11.4)$ \\
\hline $\begin{array}{l}\text { Leaving home for unavoidable } \\
\text { matters (e.g., groceries, } \\
\text { pharmacy) }\end{array}$ & $693(46.8)$ \\
\hline $\begin{array}{l}\text { Restricted at home, but } \\
\text { receiving visits (relatives, } \\
\text { friends, deliveries) }\end{array}$ & $132(8.9)$ \\
\hline $\begin{array}{l}\text { Restricted at home and not } \\
\text { receiving visits }\end{array}$ & $432(29.1)$ \\
\hline
\end{tabular}

TABLE 1 | Continued

\begin{tabular}{lc}
\hline Characteristic & $\boldsymbol{N = 1 , 4 8 2}(\%)$ \\
\hline $\begin{array}{l}\text { Going out for a walk, as } \\
\text { exercise } \\
\text { missing data }\end{array}$ & $8(0.5)$ \\
\hline
\end{tabular}

a Brazilian minimum wage salary 1,045.00 BRL (corresponding to 189.3 USD; 1st May 2020) ' Multimorbidity included stroke, Parkinson's disease, arthritis, osteoporosis, urinary and fecal incontinence, acute myocardial infarction, intestinal and depressive disease, anxiety, visual and hearing impairment, spine, overweight, hypertension and dizziness.

only when it is inevitable, such as for food supplies, health-related appointments, or to the drugstore;" "I have been receiving family members, friends, and delivery services;" "completely isolated, not going out at all;" "going out just for walking/jogging;" and "other."

\section{Data Storage and Availability}

The raw data from the baseline survey were exported from the SurveyMonkey ${ }^{\circledR}$ platform. During this stage, incomplete questionnaires were identified and excluded. Two independent researchers checked the complete submissions to search for possible duplicates or inconsistent data, such as missing consent or date of birth, bedridden status, and residents of long-term care facilities. Searches for zip codes were also conducted. A final anonymized data set was created with all eligible participants. We used only cases for which the full information for all variables of interest for the present study was available. The variables in this dataset have not been recoded or imputed. The data and codebook are available at: https://datadryad.org/stash/share/Rj8_ jEF6Tg40YBJolay_Hymqn_Azh3QedL1mPQX9kyg.

\section{Statistical Analyses}

Descriptive analyses were performed, both for the total sample and based on the investigated outcomes, using proportions and means (and standard deviation). LSA scores before and since the COVID-19 pandemic were computed for each level (home, outside home, neighborhood, town, and beyond town), and for the composite score. The difference in total scores before and since pandemic was presented as a delta ( $\Delta$ LSA). We verified whether the data set (LSA score and $\Delta$ LSA) in each group analyzed had a normal distribution using the Shapiro-Wilk test. We used the non-parametric Wilcoxon test for paired data to compare the composite score, the score for each level, and the delta score. Univariate analysis of the associations between independent variables and changes in LSA scores was evaluated by Wilcoxon signed-rank (dichotomous variables) and KruskalWallis tests (categorical variables).

To examine whether social determinants were associated with the $\Delta$ LSA, we used crude and adjusted multiple linear regression analyses. Social factors, comorbidities, and adherence to social restriction were selected as multivariate adjusted model variables. A backward stepwise method was used to obtain the final model. The results of multiple linear regression are reported as regression coefficients ( $\beta$ ) and 95\% confidence intervals (95\% CI). We evaluated the adequacy of the model by a set of statistics. The 
statistics' adjusted $R^{2}$ scores were used to verify the percentage of variance related to the decrease in $\Delta$ LSA explained by the model. The Durbin-Watson statistic was used to verify the assumption that the residuals were not correlated. We also tested for multicollinearity in the final model, according to variance inflation factors (VIF $>1.10$ ). To evaluate whether the residuals had a normal distribution, the following graphs were performed: standardized regression residuals by standardized regressionpredicted values, histogram of frequencies of standardized regression residuals, and a quantiles-quantile graph (QQ plot).

Stata 14.0 (Stata Corporation LLC, College Station, TX) was used for statistical analyses, and the level of statistical significance was set at $p<0.05$.

\section{RESULTS}

After removing incomplete and duplicate questionnaires, 1,482 participants were included who provided all information requested for the study (Figure 1). Seven hundred and ninety nine respondents (53.9\%) declared that they had answered the questionnaire by themselves; $534(36.0 \%)$ respondents had the support of a family member, friend, or others to answer the survey; and 149 (10.1\%) respondents were proxies.

Mean age was 70.0 (SD 8.14) years old. Seventy three point nine percentage were women, $53.7 \%$ were married, $61.7 \%$ reported white ethnicity, and $60.9 \%$ had 9 or more years of schooling. Approximately half of the participants reported two or more diseases, and more than $80 \%$ totally agreed that they were following social restriction measures. Participants' sociodemographic characteristics, comorbidities, and reported adherence to social restriction measures are described in Table $\mathbf{1 .}$

The mean LSA score before the COVID-19 pandemic was 64.0 (SD 26.0) and mean LSA score since the pandemic was 37.8 (SD 22.1 ), and the $\Delta$ was -26.2 (SD 25.0). A significant reduction was observed in LSA scores from Level 2 up to Level 5 ( $p<0.001$; see Figure 2 and Table 2).
Table 3 shows mean life-space mobility scores for groups of interest before and since the COVID-19 pandemic, as well as for deltas. Pardo (mixed race) individuals had a significantly lower LSA score $(p<0.001)$ before the pandemic compared with white individuals, and this situation persisted since the pandemic $(p=$ $0.005)$. A smaller, but significant reduction in LSA ( $\Delta$ LSA) $(p$ $<0.001$ ) was observed among pardo individuals compared with white individuals. A reduction in life-space mobility ( $\Delta$ LSA) was observed among women compared with men $(p<0.008)$, among older adults aged between 60 and 69 and 70 and 79 years compared with older adults aged 80 years and over $(p<0.001)$, among older people living alone $(p<0.001)$, among individuals with a high educational level ( 5 or more years of schooling) $(p<$ 0.001 ), and among individuals with a high-income level (four or more minimum wage salaries) $(p<0.001)$.

Multiple linear regression showed the relationship between $\Delta$ LSA and explanatory variables (Table 4 ). There were significant relationships between $\Delta$ LSA and male sex $(\beta=3.32,95 \% \mathrm{CI}$ $=0.33 ; 6.32)$, living alone $(\beta=-3.75,95 \% \mathrm{CI}=-7.09 ;-0.41)$, age between 70 and 79 years $(\beta=-4.95,95 \% \mathrm{CI}=-9.13 ;-0.78$; ref. 80 years and over), black race/ethnicity $(\beta=-7.76,95 \% \mathrm{CI}=$ $-13.14 ;-2.37$; ref. pardo), having more than 4 years of schooling ( $\beta=7.94,95 \% \mathrm{CI}=4.60 ; 11.28$; ref. illiterate or $1-4$ years $)$, and having an income of $\geq 4$ minimum wage salaries $(\beta=4.76,95 \%$ $\mathrm{CI}=1.77 ; 7.75 ;$ ref. $<3$ minimum wage salaries). The fit of the regression equation found in the final model was $\left[F_{(11,1,389)}=\right.$ 8.36, $p<0.001$ ], $R^{2}=0.055$.

\section{DISCUSSION}

Our results showed significant changes in life-space mobility, particularly outside of the home environment (in the neighborhood, in the town, and beyond town). Nearly a third of participants reported that they were completely restricted at home and not receiving visits, and almost half of participants were leaving home only when they needed

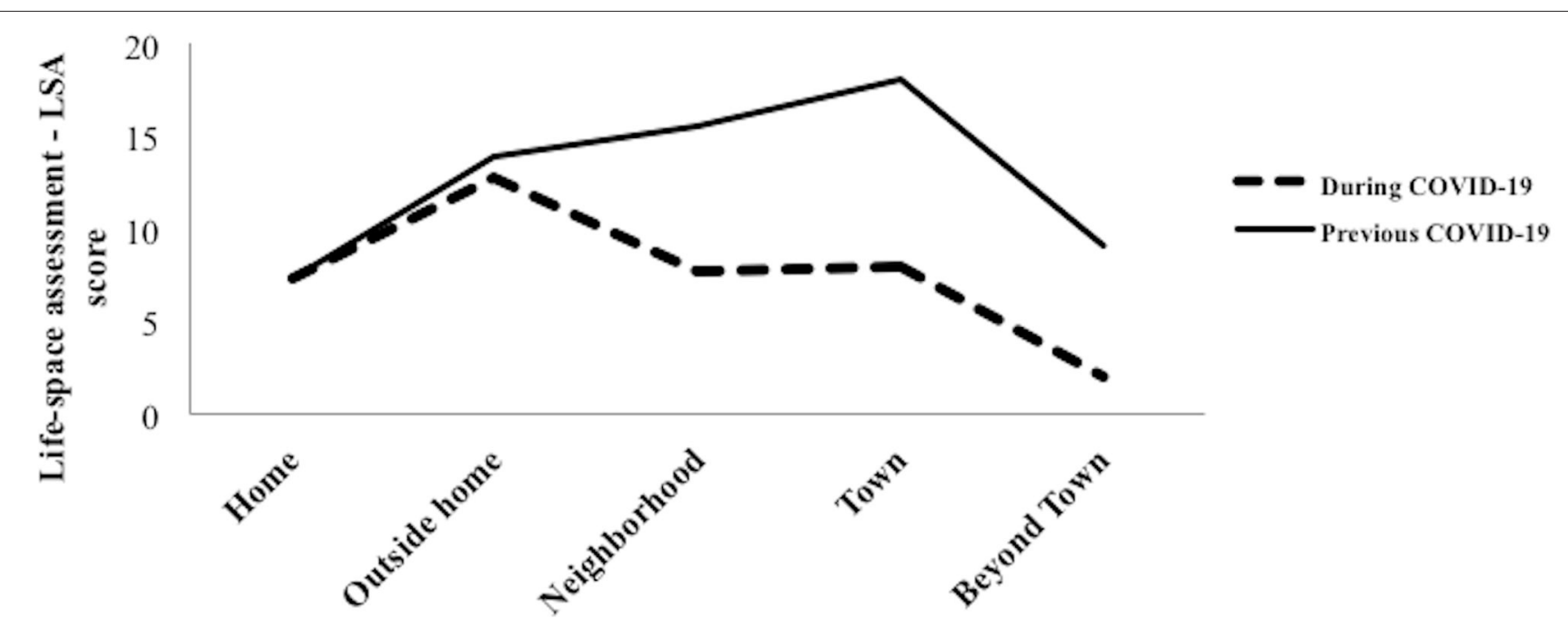

FIGURE 2 | Life-space mobility scores in each level before and since COVID-19 pandemic. 
TABLE 2 | Life-space assessment (LSA) according to five levels of mobility among Brazilian older adults living in the community before and since COVID-19 pandemic $(n=1,482)(33)$.

\begin{tabular}{|c|c|c|c|c|c|c|}
\hline $\begin{array}{l}\text { LSA levels and } \\
\text { life-space }\end{array}$ & $\begin{array}{l}\text { Level } 1 \\
\text { Home }\end{array}$ & $\begin{array}{c}\text { Level } 2 \\
\text { Outside home }\end{array}$ & $\begin{array}{c}\text { Level } 3 \\
\text { Neighborhood }\end{array}$ & $\begin{array}{l}\text { Level } 4 \\
\text { Town }\end{array}$ & $\begin{array}{c}\text { Level } 5 \\
\text { Beyond town }\end{array}$ & Total \\
\hline \multicolumn{7}{|l|}{ Before pandemic } \\
\hline Mean (SD) & $7.3(1.6)$ & $13.9(4.1)$ & $15.5(8.5)$ & $18.0(10.7)$ & $9.1(10.2)$ & $64.0(26.0)$ \\
\hline Yes (\%) & 1,459 (98.4) & 1,432 (96.6) & 1,294 (87.3) & 1,320 (89.1) & 888 (59.9) & - \\
\hline No (\%) & $23(1.6)$ & $50(3.4)$ & $188(12.7)$ & $162(10.9)$ & $594(40.1)$ & - \\
\hline \multicolumn{7}{|l|}{ Frequency (\%) } \\
\hline$<1 /$ week & $22(1.5)$ & $42(2.9)$ & $125(9.7)$ & $248(18.8)$ & $559(63.0)$ & - \\
\hline 1-3/week & $73(5.0)$ & $123(8.6)$ & $334(25.8)$ & 447 (33.8) & 218 (24.5) & - \\
\hline 4-6/week & $51(3.5)$ & $92(6.4)$ & 209 (16.2) & $224(17.0)$ & $49(5.5)$ & - \\
\hline Daily & 1,313 (90.0) & $1,175(82.1)$ & $626(48.4)$ & $402(30.4)$ & $62(7.0)$ & - \\
\hline \multicolumn{7}{|l|}{ Dependency (\%) } \\
\hline Use of assistive devices & $52(3.6)$ & $52(3.6)$ & $33(2.6)$ & $31(2.3)$ & $13(1.5)$ & - \\
\hline Assistance of a person & $40(2.7)$ & $45(3.2)$ & $54(4.2)$ & $81(6.1)$ & $59(6.6)$ & - \\
\hline $\begin{array}{l}\text { No use of devices or } \\
\text { need of assistance }\end{array}$ & 1,367 (93.7) & 1,335 (93.2) & 1,207 (93.2) & 1,209 (91.6) & $816(91.9)$ & - \\
\hline \multicolumn{7}{|l|}{ Since pandemic } \\
\hline Mean (SD) & $7.3(1.7)$ & $12.8(5.1)$ & $7.7(8.8)$ & $7.9(9.9)$ & $2.0(6.3)$ & $37.8(22.1)$ \\
\hline Yes (\%) & $1,443(97.4)$ & $1,366(92.2)$ & $793(53.5)$ & $728(49.1)$ & $188(12.7)$ & - \\
\hline No (\%) & $39(2.6)$ & $116(7.8)$ & $689(46.5)$ & $754(50.9)$ & $1,294(87.3)$ & - \\
\hline \multicolumn{7}{|l|}{ Frequency (\%) } \\
\hline$<1 /$ week & $15(1.0)$ & $52(3.8)$ & $181(22.8)$ & $244(33.5)$ & $101(53.7)$ & - \\
\hline 1-3/week & $66(4.5)$ & $180(13.2)$ & 298 (37.6) & $316(43.4)$ & 63 (33.5) & - \\
\hline 4-6/week & $62(4.2)$ & $125(9.2)$ & $84(10.6)$ & $46(6.3)$ & $7(3.7)$ & - \\
\hline Daily & $1,300(87.7)$ & 1,009 (73.9) & $230(29.0)$ & $122(16.8)$ & $17(9.0)$ & - \\
\hline \multicolumn{7}{|l|}{ Dependency (\%) } \\
\hline Use of assistive devices & $43(3.0)$ & $42(3.1)$ & $12(1.5)$ & $8(1.1)$ & $0(0.0)$ & - \\
\hline Assistance of a person & 37 (2.6) & $32(2.3)$ & $21(2.6)$ & $36(4.9)$ & $14(7.4)$ & - \\
\hline $\begin{array}{l}\text { No use of devices or } \\
\text { need of assistance }\end{array}$ & $1,363(94.5)$ & 1,292 (94.6) & $760(95.8)$ & $684(94.0)$ & $174(92.6)$ & - \\
\hline$p$-value ${ }^{a}$ & 0.363 & $<0.001$ & $<0.001$ & $<0.001$ & $<0.001$ & $<0.001$ \\
\hline
\end{tabular}

LSA, Life-Space Assessment; SD, Standard deviation.

a'Wilcoxon test.

to get groceries or go to the pharmacy. Regardless of gender and socioeconomic status, participants showed a reduction in their life-space mobility since COVID-19 pandemic. However, reductions in life-space mobility were higher among older people living alone, those aged between 70 and 79 years compared to older people aged 80 years old and over, and black individuals compared to pardo individuals, exposing underlying inequalities that might have been aggravated by the pandemic.

We found post-pandemic reductions of around 20 points in LSA scores. A score above 10 points is considered a marker of poor health outcomes (12). Similar ranges of decline in life-space mobility have been associated with future disability in performing activities of daily living (>11.7 points (34), hospital admissions (10.3-22.4 points; (35) and injurious falls (5-24 points; $(34,36)$. The continuous restriction in life-space mobility due to COVID19 might increase the risk of developing chronic conditions and functional decline.
We found older adults who were male, who had a moderate to high educational level, and who had a higher income level enjoyed more life-space mobility compared to women, individuals with lower educational and income levels. This can be partly explained by the fact that compared to older women; older men already had greater life-space mobility before the COVID19 pandemic. Older women are almost twice as likely not to work in comparison to men (37); when working, women are more frequently unpaid, doing activities such as caring for others, home-based work, or domestic chores (38). Previous studies have shown that women's life-space mobility was more frequently restricted $(6,39)$. Possibly, the life-threatening situation of the COVID-19 pandemic might have not alarmed older men. This is particularly interesting because men were found twice as likely to be at increased risk of severe COVID-19 in all age groups (3). Men were possibly less concerned than women about being contaminated and engaged in more risky activities (40). Societal expectations such as the responsibility of being the family 
TABLE 3 | Mean life-space mobility scores before and since COVID-19 pandemic and the $\Delta$ LSA (before minus since COVID-19 pandemic) according to gender, social determinants, multimorbidity and response to social restriction $(n=1,482)(33)$.

\begin{tabular}{|c|c|c|c|c|c|c|}
\hline Characteristic & $\begin{array}{c}\text { Mean LSA (SD) } \\
\text { Before } \\
\text { COVID-19 } \\
\text { pandemic }\end{array}$ & $p$-value ${ }^{a}$ & $\begin{array}{c}\text { Mean LSA (SD) } \\
\text { Since } \\
\text { COVID-19 } \\
\text { pandemic }\end{array}$ & $p$-value ${ }^{a}$ & $\begin{array}{c}\text { Mean } \Delta \text { LSA } \\
\text { (SD) }\end{array}$ & $p$-value ${ }^{a}$ \\
\hline Gender & & $<0.001$ & & $<0.001$ & & 0.008 \\
\hline Women & $62.2(25.7)$ & & $35.0(20.0)$ & & $-27.1(24.9)$ & \\
\hline Men & $69.3(26.3)$ & & $46.0(25.8)$ & & $-23.2(25.2)$ & \\
\hline $60-69$ & $70.1(24.0)$ & $<0.001$ & $42.8(22.6)$ & $<0.001$ & $-27.3(25.8)$ & $<0.001$ \\
\hline $70-79$ & $63.2(24.6)$ & $<0.001$ & $36.2(20.3)$ & $<0.001$ & $-27.0(24.4)$ & $<0.001$ \\
\hline 80 and over & $43.4(25.2)$ & Ref. & $23.5(16.4)$ & Ref. & $-19.9(22.2)$ & Ref. \\
\hline \multicolumn{7}{|l|}{ Ethnicity ${ }^{b}$} \\
\hline White & $67.0(25.1)$ & Ref. & $39.4(22.9)$ & Ref. & $-27.6(24.9)$ & Ref. \\
\hline Married & $61.0(27.4)$ & & $34.5(21.1)$ & & $-26.5(25.0)$ & \\
\hline Living alone & & $<0.001$ & & 0.476 & & $<0.001$ \\
\hline Yes & $69.3(25.9)$ & & $39.0(23.0)$ & & $-30.7(26.5)$ & \\
\hline No & $63.1(25.8)$ & & $37.9(22.1)$ & & $-25.1(24.6)$ & \\
\hline Educational level & & $<0.001$ & & $<0.001$ & & $<0.001$ \\
\hline $\begin{array}{l}\text { Low (illiterate or } 1-4 \\
\text { years of schooling) }\end{array}$ & $50.3(24.7)$ & & $32.5(20.7)$ & & $-17.9(21.0)$ & \\
\hline High (5-8/9 or more) & $69.1(24.7)$ & & $39.9(22.3)$ & & $-29.2(25.7)$ & \\
\hline $\begin{array}{l}\text { Income (minimum wage } \\
\text { salaries) }{ }^{c}\end{array}$ & & $<0.001$ & & $<0.001$ & & $<0.001$ \\
\hline$<1 / 2-3$ & $58.6(25.9)$ & & $35.8(21.1)$ & & $-22.9(23.7)$ & \\
\hline two or more & $59.5(26.5)$ & & $33.7(20.1)$ & & $-25.8(24.2)$ & \\
\hline $\begin{array}{l}\text { Social restriction } \\
\text { measures }\end{array}$ & & 0.822 & & 0.026 & & 0.082 \\
\hline $\begin{array}{l}\text { Totally and partially } \\
\text { agree and indifferent }\end{array}$ & $64.0(26.1)$ & & $37.7(22.0)$ & & $-26.3(25.1)$ & \\
\hline $\begin{array}{l}\text { Totally and partially } \\
\text { disagree }\end{array}$ & $64.9(25.8)$ & & $45.0(25.2)$ & & $-19.9(22.2)$ & \\
\hline
\end{tabular}

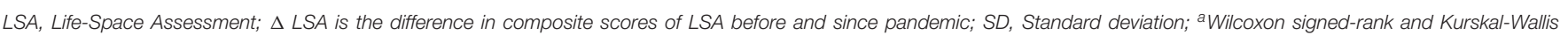

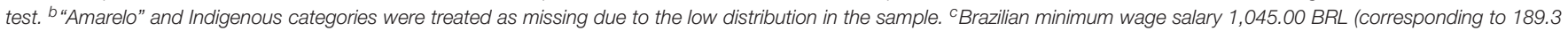

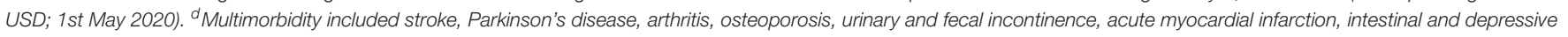
disease, anxiety, visual and hearing impairment, spine, overweight, hypertension and dizziness.

provider, a sense of invulnerability, and misleading messages from the government may have contributed to these behaviors. However, these conjectural explanations may be sample-biased due to the reduced number of men who participated in the current study (26.1\%).

Compared with older adults aged 80 and older, participants aged between 70 and 79 years experienced a greater reduction in life-space mobility, but people between 60 and 69 years did not.
In our study, among women and men aged 60-69 years old, 42 and $65 \%$ reported actively working compared to $24 \%$ of women and $40 \%$ of men aged between 70 and 79 years $(p<0.001)$. This in part might explain why this age group did not experience substantially reduced life-space mobility. Our data also revealed that multimorbidity was more prevalent among individuals aged 80 and over (92\%) and aged between 70 and 79 (86\%) compared with individuals aged between 60 and 69 years old 
TABLE 4 | Linear regression analyses to identify the association between $\Delta$ LSA (Life-space mobility) and gender, social determinants, multimorbidity and response to social restriction measures $(n=1,482)(33)$.

\begin{tabular}{|c|c|c|c|c|}
\hline \multirow[t]{2}{*}{ Characteristic } & \multicolumn{2}{|c|}{ Model crude } & \multicolumn{2}{|c|}{ Model adjusted } \\
\hline & $\beta$ crude & $95 \%$ IC & $\beta$ adjusted & $95 \%$ IC \\
\hline Gender, men (ref.: women) & 3.92 & $1.02 ; 6.81$ & 3.32 & $0.33 ; 6.32$ \\
\hline \multicolumn{5}{|l|}{ Age group (ref.: 80 years and over) } \\
\hline 60-69 years & -7.43 & $-11.07 ;-3.79$ & 3.11 & $-7.12 ; 0.92$ \\
\hline 70-79 years & -7.14 & $-11.15 ;-3.79$ & -4.95 & $-9.13 ;-0.78$ \\
\hline \multicolumn{5}{|l|}{ Ethnicity (ref: "pardo") } \\
\hline White & -5.25 & $-8.08 ;-2.41$ & -1.96 & $-4.91 ; 1.00$ \\
\hline Black & -7.70 & $-13.11 ;-2.29$ & -7.76 & $-13.14 ;-2.37$ \\
\hline Living alone & -5.14 & $-8.46 ;-1.82$ & -3.75 & $-7.09 ;-0.41$ \\
\hline Complete years of schooling > 4 years (ref.: Illiterate or $1-4$ ) & 11.30 & $8.48 ; 14.11$ & 7.94 & $4.60 ; 11.28$ \\
\hline Income $\geq 4$ minimum wage salaries (ref.: $<3$ ) & 8.59 & $5.99 ; 11.18$ & 4.76 & $1.77 ; 7.75$ \\
\hline Occupation active (ref.: inactive/unemployed) & -1.61 & $-4.25 ; 1.03$ & 0.57 & $-2.23 ; 3.37$ \\
\hline Multimorbidity ${ }^{\mathrm{b}} 0-1$ (ref.: two or more) & -0.58 & $-3.16 ;-1.99$ & -1.12 & $-1.53 ; 3.78$ \\
\hline $\begin{array}{l}\text { Social restriction measures (total and partial disagree and } \\
\text { indifferent) (ref.: total and partial agree) }\end{array}$ & 6.44 & $-0.83 ; 13.70$ & 3.34 & $-4.00 ; 10.69$ \\
\hline
\end{tabular}

Adjusted $R^{2}=0.0546 ; F_{11,1389}=8.36, d f=11$ of $24 ; p<0.001 . \beta$, standardized regression coefficient; Cl, confidence interval.

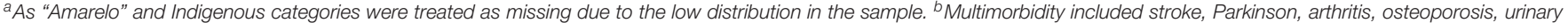
and fecal incontinence, acute myocardial infarction, intestinal and depressive disease, anxiety, visual and hearing impairment, spine, overweight, hypertension and dizziness.

Model adjusted for sex, age, race, living alone, schooling, income, occupation, multimorbidity, and response to social restriction measures (e.g., lockdown, stay-at-home recommend).

$(80 \% ; p<0.001)$. Common reported health conditions that were more prevalent with increasing age were diabetes, hypertension, congestive heart failure, hearing loss, urinary incontinence, and dizziness. Being more vulnerable to severe COVID-19 might have alarmed the oldest individuals and discouraged them from moving around.

Higher reductions in life-space mobility were observed among black individuals compared to older pardo individuals. Employment inequalities in this population might in part explain this reduction. Approximately $70 \%$ of older adults in Brazil are retired or pensioners, and $15.6 \%$ still work to supplement their income (41). Insufficient income for daily expenses is more frequently reported by black (50.3\%) and pardo $(51,1 \%)$ older adults in Brazil compared with white older adults (38.6\%; (42)), pushing vulnerable populations to seek informal jobs. These jobs were highly restricted during the early months of the COVID19 pandemic (i.e., informal market, street vending jobs, and domestic jobs; (43) and this situation might have contributed for the reduction of life-space among black individuals.

Systemic disadvantageous conditions, such as high health illiteracy (44), poor health (multiple comorbidities), racism, and poor housing conditions with many people of different generations occupying the same spaces (42) may have influenced how older black people coped with the social and economic restrictions resulting from the pandemic. In our study, black and pardo individuals had significantly lower incomes compared to whites (74 vs. 79 vs. $53 \%$; $p<0.001$, respectively) and were also less educated (illiterate or 1-4 years of schooling: 39 vs. 40.5 vs. $19 \%$; $p<0.001$, respectively). Low socioeconomic status and physical inactivity during the pandemic combined with underlying health conditions that are common in this population may increase the risk of poor management of non-communicable diseases, disability, and frailty. A population-based study in Brazil showed a worse health pattern for black individuals, with substantially higher prevalence ratios for hypertension, diabetes, stroke, and cognitive decline (42).

Living alone was another social determinant that accounted for a greater restriction in life-space mobility during COVID19. In Brazil, more than 4.3 million older people were living alone before the pandemic (45), and nearly $60 \%$ were women aged between 65 and 74 years (46). In the present study, 85\% of the participants who lived alone were women, and nearly $60 \%$ were aged between 60 and 69 years. A Brazilian populationbased study of 11,967 older adults living alone confirmed a higher prevalence of this household type among women and showed that older people living alone more frequently reported musculoskeletal conditions, hearing loss, falls, and limitations to instrumental activities of daily living (47). Older people living alone are more likely to face emergency department visits and to have general practitioner appointments compared to older adults living with others (48). Unmet basic needs, social isolation and disruption of health services during the COVID-19 pandemic might increase the risk of loneliness, malnutrition, and functional decline (49). Older women in particular are at greater risk of financial abuse and lack of care (50).

Older people with moderate to high educational levels and higher income levels had greater life-space mobility scores before the pandemic compared to the group with lower education and income levels; for them, the impact of the COVID-19 pandemic contributed less to reduction in life-space mobility. These groups were able to appraise health-related information and use resources to adopt shielding strategies. Higher levels of education and social status have been associated with higher health literacy (51). However, it is also argued that higher 
health literacy scores are associated with lower fear of COVID19 and lower likelihood of depression (51), which may have influenced better educated older people to take risks. Having a private vehicle for transportation and access to locations outside urban centers might have increased the areas wealthy older people moved around. Socioeconomic inequalities from birth onward favor better health trajectories for individuals with higher educational and income levels, and these gaps commonly increase with age (52).

The implications of our findings are 2-fold. First, our results underline the need to structure urgent comprehensive responses to mitigate pandemic consequences among older adults living alone, among black individuals, and for people with lower income and education levels. Prioritized actions should be set up urgently to assist these vulnerable groups in the community, strengthening existing policies in the public sector, particularly the Family Strategy Program in the National Health Service (or SUS). In Brazil, the older population (more than $80 \%$ ) largely relies on public health care, and this percentage is even higher among Afro-Brazilians and the poor (53). Integrated person-centered care can include life-space assessment and monitoring over time, helping service providers and health care teams capture short- and long-term functional consequences of the pandemic. The provision of long-term care services at the national and subnational levels should also be envisioned.

Second, innovative digital technologies should be envisioned to scale up best-buy interventions, such as digital platforms to deliver physical activity and rehabilitation programs (54). Mobile apps that can track life-space mobility over time, creating alerts for unusual reductions, are promising resources $(55,56)$. Digital technologies are increasingly important strategies for engaging older people and for providing access to a wide range of services. The use of digital technology has been increasing annually among older people. In Brazil, the proportion of older adults who access the Internet has increased from $24.7 \%$ in 2016 to $31.1 \%$ in 2017 (57), and about $80 \%$ of households in the Southeast region have Internet access (58). However, digital illiteracy and high costs to purchase mobile phones with internet connection packages are still a greater barrier, affecting the ability of low-income older people to use services that are being required during the pandemic (59). Public-private partnerships can ensure that services are available to these groups to prevent further aggravation of health inequities during COVID-19 pandemic.

The results of the present analysis have some limitations. Some geographical regions of Brazil were less represented, such as the south and central regions. However, the southeast region, which is the most populated and contains a higher proportion of older people, is well-represented in our sample. Although we made efforts to reach vulnerable older adults in some urban communities (i.e., slums), these areas may be underrepresented, but face-to-face interviews were unsafe for both participants and researchers during the COVID-19 pandemic. Recall bias is also possible, since the participants self-reported their life-space mobility conditions before COVID-19. We also cannot assume that the restriction in life-space mobility that we observed is solely related to the pandemic. Timing and intensity of the pandemic might have influenced the reductions in life-space mobility. Furthermore, we used a broad and general question to capture adherence behavior to stay-at-home and social distancing recommendations. That question alone might not be able to capture all older adults' views and experiences during the pandemic.

Mobility concerning life spaces includes not only walking, but also other modes of transport (e.g., subway, train, private vehicle, or bus), particularly for moving beyond one's neighborhood (town and beyond town zones). Future studies should specifically address restrictions on transportation during the pandemic, which may have varied according to the sizes of cities, population density, and regulatory policies determined by local governments to deal with coronavirus transmission. Environmental barriers and enablers inside the house and in the community also require further studies. This study focuses on the first wave of a cohort study and is cross-sectional, which limited causal relations and the determinations of trajectories of life-space mobility for different groups. We believe that the results of a 12-month follow-up will help to better understand the shortand long-term impacts of the COVID-19 pandemic on lifespace mobility.

Social restriction measures due to a pandemic caused substantial limitations in older adults' life-space mobility in Brazil. Social inequalities should be recognized, and concerted action should be taken to overcome the deterioration in life-space mobility among the most vulnerable groups of older people. Worldwide, failure to minimize health inequalities-amplified by the pandemic-may jeopardize the desired achievements of the Decade of Healthy Aging (60).

\section{DATA AVAILABILITY STATEMENT}

The datasets presented in this study can be found in online repositories. The names of the repository/repositories and accession number(s) can be found in the article/supplementary material.

\section{ETHICS STATEMENT}

The studies involving human participants were reviewed and approved by Ethics Committee of Universidade Cidade de São Paulo (protocol number 4.032.523). The ethics committee waived the requirement of written informed consent for participation.

\section{AUTHOR CONTRIBUTIONS}

MP participated in concept design, data collection, data analysis, interpretation, drafting, critical revision, and approval of the article. CL, ML, and RS participated in concept design, data collection, data analysis, interpretation, critical revision, and approval of the article. JA participated in data collection, data analysis, interpretation, critical revision, and approval of the 
article. AS, PP, FT-S, DP, and PB participated data collection, interpretation, critical revision, and approval of the article. ED participated interpretation, critical revision, and approval of the article. All authors contributed to the article and approved the submitted version.

\section{FUNDING}

MRP has received a researcher productivity grant (309838/2017-7) from the Brazilian National Council for Scientific and Technological Development.

\section{REFERENCES}

1. Hall G, Laddu DR, Phillips SA, Lavie CJ, Arena R. A tale of two pandemics: How will COVID-19 and global trends in physical inactivity and sedentary behavior affect one another? Prog Cardiovasc Dis. (2021) 64:108-10. doi: 10.1016/j.pcad.2020.04.005

2. Morley JE, Vellas B. Editorial: COVID-19 and older adults. J Nutr Health Aging. (2020) 24:364-5. doi: 10.1007/s12603-0201349-9

3. Clark A, Jit M, Warren-Gash C, Guthrie B, Wang HHX, Mercer SW, et al. Global, regional, and national estimates of the population at increased risk of severe COVID-19 due to underlying health conditions in 2020: a modelling study. Lancet Glob Health. (2020) 8:e1003-17. doi: 10.1016/S2214-109X(20)30264-3

4. Lewnard JA, Lo NC. Scientific and ethical basis for social-distancing interventions against COVID-19. Lancet Infect Dis. (2020) 20:631-3. doi: 10.1016/S1473-3099(20)30190-0

5. Carel H, Ratcliffe M, Froese T. Reflecting on experiences of social distancing. Lancet. (2020) 396:87-8. doi: 10.1016/S0140-6736(20)31485-9

6. Al Snih S, Peek KM, Sawyer P, Markides KS, Allman RM, Ottenbacher KJ. Life-space mobility in Mexican Americans aged 75 and older. $J$ Am Geriatr Soc. (2012) 60:532-7. doi: 10.1111/j.1532-5415.2011.0 3822.x

7. Curcio CL, Alvarado BE, Gomez F, Guerra R, Guralnik J, Zunzunegui MV. Life-Space Assessment scale to assess mobility: validation in Latin American older women and men. Aging Clin Exp Res. (2013) 25:553-60. doi: 10.1007/s40520-013-0121-y

8. Barberia LG, Gomez EJ. Political and institutional perils of Brazil's COVID-19 crisis. Lancet. (2020) 396:367-8. doi: 10.1016/S0140-6736(20)31681-0

9. Xue QL, Fried LP, Glass TA, Laffan A, Chaves PH. Life-space constriction, development of frailty, and the competing risk of mortality: the Women's Health And Aging Study I. Am J Epidemiol. (2008) 167:240-8. doi: 10.1093/aje/kwm270

10. Rantakokko M, Portegijs E, Viljanen A, Iwarsson S, Rantanen T. Life-space mobility and quality of life in community-dwelling older people. J Am Geriatr Soc. (2013) 61:1830-2. doi: 10.1111/jgs.12473

11. Peel C, Sawyer Baker P, Roth DL, Brown CJ, Brodner EV, Allman RM. Assessing mobility in older adults: the UAB Study of Aging Life-Space Assessment. Phys Ther. (2005) 85:1008-119. doi: 10.1093/ptj/85.10.1008

12. Rantanen T, Eronen J, Kauppinen M, Kokko K, Sanaslahti S, Kajan N, et al. Life-Space Mobility and active aging as factors underlying quality of life among older people before and during COVID-19 lock-down in Finland - a longitudinal study. J Gerontol A Biol Sci Med Sci. (2021) 76:e60-7. doi: $10.1093 /$ gerona/glaa274

13. Saraiva MD, Apolinario D, Avelino-Silva TJ, et al. The impact of frailty on the relationship between life-space mobility and quality of life in older adults during the COVID-19 pandemic. J Nutr Health Aging. (2020). doi: 10.1007/s12603-020-1532-z. [Epub ahead of print].

14. Rantanen T, Portegijs E, Kokko K, Rantakokko M, Tormakangas T, Saajanaho M. Developing an assessment method of active aging: University of Jyvaskyla active aging scale. J Aging Health. (2019) 31:1002-24. doi: 10.1177/0898264317 750449

\section{CANSORT SCI AFFILIATIONS}

Adriana Guedes Carlos, Professor Aurelio Dias Santos, Professor Etiene Oliveira da Silva Fittipaldi, Professor Hércules Campos, Professor Juliana Maria Gazzola, Dr. Mirian Moreira, Professor Mônica Beatriz Ferreira, Nayara Tasse de Oliveira Cirino, Professor Renata Oliveira Dantas, Renata dos Ramos Varanda, Professor Suzana Albuquerque de Moraes, Professor Guilherme Medeiros de Alvarenga, Professor Cristina Cristovão Ribeiro da Silva, Sarah Giulia Bandeira Felipe and Professor Lygia Paccini Lustosa (in memoriam).

15. Portegijs E, Tsai LT, Rantanen T, Rantakokko M. Moving through life-space areas and objectively measured physical activity of older people. PLoS ONE. (2015) 10:e0135308. doi: 10.1371/journal.pone.0135308

16. Tsai LT, Rantakokko M, Rantanen T, Viljanen A, Kauppinen M, Portegijs E. Objectively measured physical activity and changes in life-space mobility among older people. J Gerontol A Biol Sci Med Sci. (2016) 71:1466-71. doi: 10.1093/gerona/glw042

17. Polku, H., Mikkola, T.M., Portegijs, E., Rantakokko, M., Kokko, K., Kauppinen, M., et al. (2015). Life-space mobility and dimensions of depressive symptoms among community-dwelling older adults. Aging Ment. Health 19, 781-789. doi: 10.1080/13607863.2014.977768

18. Crowe M, Andel R, Wadley VG, Okonkwo OC, Sawyer P, Allman RM. Life-space and cognitive decline in a community-based sample of African American and Caucasian older adults. J Gerontol A Biol Sci Med Sci. (2008) 63:1241-45. doi: 10.1093/gerona/63.11.1241

19. Silberschmidt, S., Kumar, A., Raji, M.M., Markides, K., Ottenbacher, K.J., and Al Snih, S. (2017). Life-space mobility and cognitive decline among Mexican Americans aged 75 years and older. J. Am .Geriatr. Soc. 65, 1514-1520. doi: 10.1111 /jgs.14829

20. Pelicioni PHS, Lord SR. COVID-19 will severely impact older people's lives, and in many more ways than you think! Braz J Phys Ther. (2020) 24:293-4. doi: 10.1016/j.bjpt.2020.04.005

21. Roschel H, Artioli GG, Gualano B. Risk of increased physical inactivity during COVID-19 outbreak in older people: a call for actions. J Am Geriatr Soc. (2020) 68:1126-8. doi: 10.1111/jgs.16550

22. Cunningham C, O' Sullivan R, Caserotti P, Tully MA. Consequences of physical inactivity in older adults: a systematic review of reviews and metaanalyses. Scand J Med Sci Sports. (2020) 30:816-27. doi: 10.1111/sms.13616

23. Kirwan R, Mccullough D, Butler T, Perez De Heredia F, Davies IG, Stewart C. Sarcopenia during COVID-19 lockdown restrictions: long-term health effects of short-term muscle loss. Geroscience. (2020) 42:1547-78. doi: 10.1007/s11357-020-00272-3

24. Douglas M, Katikireddi SV, Taulbut M, Mckee M, Mccartney G. Mitigating the wider health effects of covid-19 pandemic response. BMJ. (2020) 369:m1557. doi: 10.1136/bmj.m1557

25. Almeida FP, de Lima MKG, Gomes DC, de Souza EF. Logistic regression models and classification tree for deaths and recovered patients records of Covid-19 in the State of Minas Gerais, Brazil. Int J Adv Eng Res. (2020) 10:150-60. doi: 10.22161/ijaers.710.16

26. De Biase S, Cook L, Skelton DA, Witham M, Ten Hove R. The COVID-19 rehabilitation pandemic. Age Ageing. (2020) 49:696-700. doi: 10.1093/ageing/afaa118

27. Garnier-Crussard A, Forestier E, Gilbert T, Krolak-Salmon P. Novel Coronavirus (COVID-19) epidemic: what are the risks for older patients? J Am Geriatr Soc. (2020) 68:939-40. doi: 10.1111/jgs.16407

28. Simoes M, Garcia IF, Costa LDC, Lunardi AC. Life-Space Assessment questionnaire: Novel measurement properties for Brazilian communitydwelling older adults. Geriatr Gerontol Int. (2018) 18:783-9. doi: $10.1111 /$ ggi.13263

29. Taylor JK, Buchan IE, Van Der Veer SN. Assessing life-space mobility for a more holistic view on wellbeing in geriatric research and clinical practice. Aging Clin Exp Res. (2019) 31:439-45. doi: 10.1007/s40520-018-0999-5 
30. Baker PS, Bodner EV, Allman RM. Measuring life-space mobility in community-dwelling older adults. J Am Geriatr Soc. (2003) 51:1610-4. doi: 10.1046/j.1532-5415.2003.51512.x

31. Groll DL, To T, Bombardier C, Wright JG. The development of a comorbidity index with physical function as the outcome. J Clin Epidemiol. (2005) 58:595602. doi: 10.1016/j.jclinepi.2004.10.018

32. Banerjee S. Multimorbidity-older adults need health care that can count past one. Lancet. (2015) 385:587-9. doi: 10.1016/S0140-6736(14)61596-8

33. Monica P, et al. Impact of COVID-19 Pandemic on Life-Space Mobility of Older Adults Living in Brazil: REMOBILIZE Study. Dryad, Dataset (2020).

34. Portegijs E, Rantakokko M, Viljanen A, Sipila S, Rantanen T. Identification of older people at risk of ADL disability using the life-space assessment: a longitudinal cohort study. J Am Med Dir Assoc. (2016) 17:410-4. doi: 10.1016/j.jamda.2015.12.010

35. Brown CJ, Roth DL, Allman RM, Sawyer P, Ritchie CS, Roseman JM. Trajectories of life-space mobility after hospitalization. Ann Intern Med. (2009) 150:372-8. doi: 10.7326/0003-4819-150-6-200903170-00005

36. Portegijs E, Rantakokko M, Viljanen A, Sipila S, Rantanen T. Is frailty associated with life-space mobility and perceived autonomy in participation outdoors? A longitudinal study. Age Ageing. (2016) 45:550-3. doi: 10.1093/ageing/afw072

37. Dantas RG, Perracini MR, Guerra RO, Ferriolli E, Dias RC, Padula RS. What are the sociodemographic and health determinants for older adults continue to participate in work? Arch Gerontol Geriatr. (2017) 71:136-41. doi: 10.1016/j.archger.2017.04.005

38. King MC. Occupational segregation by race and sex in Brazil, 1989-2001. Rev Black Polit Econ. (2009) 36:113-25. doi: 10.1007/s12114-009-9038-2

39. Eronen J, Von Bonsdorff M, Rantakokko M, Portegijs E, Viljanen A, Rantanen T. Socioeconomic status and life-space mobility in old age. J Aging Phys Act. (2016) 24:617-23. doi: 10.1123/japa.2015-0196

40. Griffith D, Sharma G, Holliday C, Enyia O, Valliere M, Semlow A, et al. Men and COVID-19: a biopsychosocial approach to understanding sex differences in mortality and recommendations for practice and policy interventions. Prev Chronic Dis. (2020) 17:200247. doi: 10.5888/pcd17.200247

41. Tramujas Vasconcellos Neumann L, Albert SM. Aging in Brazil. Gerontologist. (2018) 58:611-7. doi: 10.1093/geront/gny019

42. Silva AD, Rosa T, Batista LE, Kalckmann S, Louvison MCP, Teixeira D, et al. Racial inequities and aging: analysis of the 2010 cohort of the Health, Welfare and Aging Study (SABE). Rev Bras Epidemiol. (2019) 21:e180004. doi: 10.1590/1980-549720180004.supl.2

43. ILO. Impact of the COVID-19 Crisis on Loss of Jobs and Hours Among Domestic Workers. Switzerland: International Labour Organization (2020).

44. Howard DH, Sentell T, Gazmararian JA. Impact of health literacy on socioeconomic and racial differences in health in an elderly population. J Gen Intern Med. (2006) 21:857-61. doi: 10.1111/j.1525-1497.2006.00530.x

45. IBGE. PNAD Contínua TIC 2017: Internet Chega a Três em Cada Quatro Domicílios do País. Brasilia: iBGE. Available online at: https://ibge.gov.br (accessed November 3, 2020).

46. Reher D, Requena M. Living alone in later life: a global perspective. Popul Dev Rev. (2018) 44:427-54. doi: 10.1111/padr.12149

47. Negrini ELD, Do Nascimento CF, Da Silva A, Antunes JLF. Elderly persons who live alone in Brazil and their lifestyle. Rev Bras Geriatr Gerontol. (2018) 21:523-31. doi: 10.1590/1981-22562018021.18 0101

48. Dreyer K, Steventon A, Fisher R, Deeny SR. The association between living alone and health care utilisation in older adults: a retrospective cohort study of electronic health records from a London general practice. BMC Geriatr. (2018) 18:269. doi: 10.1186/s12877-0180939-4
49. Berg-Weger M, Morley JE. Editorial: Loneliness and social isolation in older adults during the COVID-19 pandemic: implications for gerontological social work. J Nutr Health Aging. (2020) 24:456-8. doi: 10.1007/s12603-0201366-8

50. Rodrigues RAP, Dos Santos AMR, Pontes MLF, Monteiro EA, Fhon JRS, et al. Report of multiple abuse against older adults in three Brazilian cities. PLoS ONE. (2019) 14:e0211806. doi: 10.1371/journal.pone.02 11806

51. Do BN, Nguyen PA, Pham KM, Nguyen HC, Nguyen MH, Tran CQ, et al. Determinants of health literacy and its associations with health-related behaviors, depression among the older people with and without suspected COVID-19 symptoms: a multi-institutional study. Front Public Health. (2020) 8:581746. doi: 10.3389/fpubh.2020.581746

52. Diaz MD. Socio-economic health inequalities in Brazil: gender and age effects. Health Econ. (2002) 11:141-54. doi: 10.1002/hec.649

53. Kalache A, da Silva A, Giacomin KC, de Lima KC, Ramos LR, Louvison $\mathrm{M}$, et al. Aging and inequalities: social protection policies for older adults resulting from the Covid-19 pandemic in Brazil. Brazil. Rev Bras Geriatr Gerontol. (2020) 23:e200122. doi: 10.1590/1981-22562020023.200122

54. Richardson SJ, Carroll CB, Close J, Gordon AL, O’brien J, Quinn TJ, et al. Research with older people in a world with COVID-19: identification of current and future priorities, challenges and opportunities. Age Ageing. (2020) 49:901-6. doi: 10.1093/ageing/afaa149

55. Chung, M.H., Leung, S.F., and Valimaki, M. (2020). Use of tracking technology to examine life-space mobility among people with depression: a systematic review protocol. BMJ Open 10:e034208. doi: 10.1136/bmjopen-2019-034208

56. Ho, S. H., Tan, D. P. S., Tan, P. J., Ng, K. W., Lim, Z. Z. B., Ng, I. H. L., et al. (2020). The development and validation of a prototype mobility tracker for assessing the life space mobility and activity participation of older adults. BMC Geriatr. 20:251. doi: 10.1186/s12877-020-01649-x

57. IBGE (2018). Projeção da Populaạão 2018: número de habitantes do país deve parar de crescer em 2047 [Online]. IBGE. Available online at: https:// agenciadenoticias.ibge.gov.br/agencia-sala-de-imprensa/2013-agenciade-noticias/releases/21837-projecao-da-populacao-2018-numero-dehabitantes-do-pais-deve-parar-de-crescer-em-2047 (accessed November 4, 2020).

58. IBGE (2018). Acesso à internet e a televisão e posso de telefone móvel celular pra uso pessoal [Online]. IBGE. Available online at: https://biblioteca.ibge.gov.br/ visualizacao/livros/liv101631_informativo.pdf (accessed November 4, 2020).

59. Nishijima M, Ivanauskas TM, Sarti FM. Evolution and determinants of digital divide in Brazil (2005-2013). Telecomm Policy. (2017) 41:12-24. doi: 10.1016/j.telpol.2016.10.004

60. WHO. Decade of healthy ageing. The global strategy and action plan on ageing and health 2016-2020: towards a world in which everyone can live a long and healthy life. In: Seventy-third World Health Assembly, Geneva, 5 May 2020. Geneva: World Health Organization (2020).

Conflict of Interest: The authors declare that the research was conducted in the absence of any commercial or financial relationships that could be construed as a potential conflict of interest.

Copyright (C) 2021 Perracini, de Amorim, Lima, da Silva, Trombini-Souza, Pereira, Pelicioni, Duim, Batista, dos Santos, de Lima and the REMOBILIZE Research Network (CANSORT-SCI). This is an open-access article distributed under the terms of the Creative Commons Attribution License (CC BY). The use, distribution or reproduction in other forums is permitted, provided the original author(s) and the copyright owner(s) are credited and that the original publication in this journal is cited, in accordance with accepted academic practice. No use, distribution or reproduction is permitted which does not comply with these terms. 